\title{
Pollution Profiling and Particle Size Distribution within Permeable Paving Units - With and Without a Geotextile
}

\author{
Jennifer Mullaney*, Päivi Rikalainen, Chris Jefferies. \\ University of Abertay Dundee, Urban Water Technology Centre, Level 5 Kydd Building, Bell \\ Street, Dundee DDI 1HG, Scotland
}

Submitted 31st July 2011, Revised $16^{\text {th }}$ August 2011

\begin{abstract}
Purpose - The aim of this paper is to investigate the sediment and pollution profiling and particle size distribution with depth within permeable paving structures both with and without a geotextile.
\end{abstract}

Design/methodology/approach - Test rigs set up in an earlier pilot study were used for four separate but linked studies. Street dust was applied to rigs $\mathrm{C}$ and $\mathrm{D}$ to determine the retention of sediments. Heavy metals together with street dust were applied to rig A and B (previously control rigs) to determine the effect of sediment on the pollution removal capabilities of the test rigs. Following the application of sediment, rigs A and B were carefully taken apart to determine pollution profiles and particle size distributions.

Findings - The findings reveal that sediment does have an effect on the metal removal capabilities of permeable paving systems, but there was minimal difference between the rigs with a geotextile and without. Pollution profiling within the test rigs identified that the greatest concentration of metals was in the surface sediment and that both rigs removed similar percentages but the concentrations of metals were distributed differently. It was also found that between 10 and 15 years of sediment application paving rigs began to 'block' causing reduced infiltration rates. Unfortunately it is difficult to explain the variations of particle size distributions found with depth in the paving structure. It had been expected to find progressively higher proportions of finer material with depth. However, the reverse was true, with a higher proportion of fines in the sediment applied to the surface and a progressive increase in the proportion of coarse material with depth

Practical implications - The conclusions confirm the effects of sediment within a permeable paving structure and indicate the loading at which the infiltration rates become affected. These results may help to determine a maintenance programme however this would require further research.

Originality/value - The paper provides a comparative study on pollution and sediment profiling within a permeable paving structure both with and without the inclusion of an upper geotextile. It provides valuable insight into the amount of sediment on paving before it becomes blocked. The methodology and results reported in this research could be used for further studies to provide more evidence as to whether the inclusion of an upper geotextile is beneficial.

Keywords - Permeable Paving SUDS, Geotextile, Pollutant Removal, Car Park, Clogging, Pollution Profiling, Particle Size Distribution.

Paper type - Research paper

\section{Introduction}

Urban runoff is one of the major causes of pollution, coming mainly from micropollutants deposited on roads and parking areas. The management of stormwater is vital in reducing these pollutants and in reducing or delaying the volume of water discharging to the sewer or 
receiving water body. Many water management systems, which come under the generic title of sustainable urban drainage (SUDS), are difficult to retrofit and implement on a large scale due to space and cost constraints. As a consequence, permeable pavement systems have become a popular solution worldwide in reducing the burden of increased runoff on urban waterways by restoring the infiltration and hydraulic functions of natural systems. Maintenance has emerged as a major issue in the study of sustainable urban drainage systems (SUDS). Clogging is of concern for permeable paving since it is perceived that the hydrological performance will worsen and weed growth will give increasing problems for permeable pavements if they are not maintained properly. As a result, different manufacturers have entered the market and there is a need to understand performance in a wide range of circumstances.

Woods-Ballard et al (2007) state that "geotextiles in the upper layers can adversely affect the infiltration rate if they become blinded with fine silt". This is a mean-worded statement for the principal design and operational guidance in the UK, since it is not usable information and shows that better maintenance guidance and studies of the effect of maintenance on behaviour are needed.

Geotextile membranes are generally placed at one of two levels within permeable paving structures; at the upper level separating the bedding layer and sub base; and at the lower level separating the sub base from the sub grade. Claims have been made, implicitly or explicitly, that a geotextile is needed to achieve good environmental performance (e.g. Puehmier \& Newman (2008), Scholz and Graboweiki (2007)). While there may be good structural reasons for incorporating a geotextile membrane, the water quality benefits are questionable.

A recent literature review by two of the authors showed that a large number of studies have been undertaken concerning the pollutant removal properties of permeable pavements, their hydraulic functions and the effects of clogging. Gilbert \& Clausen (2006) compared the runoff quality from asphalt, crushed stone and paver driveways in Connecticut. A study by Dierkes et al (2005) evaluated the pollution retention capacity of a paving area of lead, zinc, cadmium and copper. In the latter study five laboratory rigs, each containing different joint fillers, showed high retention abilities of all the metals. It was found that the overall efficiency for cadmium and lead was over $99 \%$ and for copper $98 \%$ with zinc slightly greater than $94 \%$.

The presence of an upper geotextile was found to be particularly important during oil retention studies. Pratt et al (1999) conducted both a laboratory and field study to simulate crank case leakage. The apparatus contained both an upper and lower geotextile, see location of upper geotextile in Figure 1. It was observed from the experiment that only $2.4 \%$ of the oil applied was not retained within the system and that a structure's efficiency in degrading oil is dependent on nutrient supply. Newman et al (2001) also found that permeable paving had high oil removal with $99.6 \%$ removal rate compared to $49.6 \%$ within a comparison system built using asphalt.

Various studies have been undertaken on the effects of clogging and the rates at which it occurs. Yong et al (2008) compared the ponding depths on three permeable paving surfaces using depths of ponding to indicate levels of clogging. It was found that with some types of blocks, clogging on the geotextile surface limited infiltration and only one type of block (Permapave) was able to cope with the 100yr storm. Gilbert and Clausen (2006) found that when comparing asphalt, paved and crushed stone driveways, the infiltration rates were zero, 11.2 and $9 \mathrm{~cm} / \mathrm{h}$ respectively and the rates for both paved and crushed stone driveways declined somewhat over the course of this study. This decline is likely to be a result of fine particles clogging the openings in the pavers and the soil surface at the stone-surface interface (Gilbert and Clausen, 2006). Pezzaniti et al (2009) simulated the application of 35 years of 
sediment on a laboratory set up and the results showed reductions of $59-75 \%$ in hydraulic conductivity, with average sediment retention of $94 \%$. These authors reported that there was no significant difference between blocks which were cleaned and to those that were not. Bean et al (2004) studied the differences in infiltration rates on two different pavers, concrete grid pavers and permeable interlocking concrete pavers (PICP), and the effects of maintenance. To simulate maintenance the top layer of void material $(1.3-1.9 \mathrm{~cm})$ was removed to mimic removal by a vacuum truck or street sweeper. Sixteen sites were constructed with concrete grid pavers, 14 of which were maintained. Of the maintained sites 13 had much higher infiltration rates compared to the unmaintained. When comparing mean values the maintained sites had an increased permeability by $66 \%$. Of the 11 sites with PICP 4 sites had exposed fine soils nearby e.g. gravel drive, river bed, beach, construction sites. Sites located near areas with exposed fine soils (fines) were found to have substantially lower infiltration rates than areas free from fines. "Infiltration rates of PICP filled with gravel are not limited by their surface infiltration capacity provided they are sited in areas free of soil disturbances" (Bean et al, 2004). Average infiltration rates were $20,00 \mathrm{~cm} / \mathrm{hr}$, whereas for sites located near exposed fine soil rates were $61 \mathrm{~cm} / \mathrm{hr}$, a decrease of almost $97 \%$.

Van Duin et al (2008) carried out a field study and laboratory experiments on the infiltration capacities and particle size distributions of sediment within two types of test rig; porous asphalt and Eco-stone open joint paving blocks. Results from the field study showed that porous asphalt clogged much quicker then the Eco-stone pavers within the first year of operation. The laboratory results showed $90-96 \%$ removal of suspended solids in both test units. Particle size distribution results showed that sediment removal occurred throughout the paving structure but filtration action occurred primarily by the geotextile. Deposited material below the geotextile was found to be significantly finer compared to that above. The results from both experiments (field and laboratory) contradicted each other. The laboratory results showed "filtration primarily took place at the surface of the pavement; this may be due to the influent characteristics and the lack of 'crust' formation in the laboratory" (Van Duin et al, 2008).

Pratt et al (2002) carried out a laboratory study of the infiltration performance of permeable pavement surface blocks with and without silt addition. The test rigs all had an upper geotextile. The procedure was first carried out with no silt addition, and then two different silts were separately applied manually to the spaces between the blocks; manufactured and sampled. Results from the study again indicated that infiltration rates were much lower in rigs where sediment had been applied. "However when comparing the two sets of results where different silts are compacted in the same way it is evident that infiltration performance is much lower with the sampled silt that the manufactured silt" (Pratt et al, 2002). Where 50\% of the mass of silts had been removed after initial compaction there was a significant increase in infiltration, suggesting that mechanical cleansing removing silt could enhance the pavements performance and prevent if becoming heavily blocked.

The review highlighted that none produced directly comparable results of paving construction with and without an upper geotextile layer. This means that there is no experimental evidence which supports the importance of an upper geotextile in delivering enhanced outflow water quality and improved system hydraulics. From an initial study by Mullaney et al (2011) to determine the performance of block paving with and without a geotextile in the sub-base, it was evident that more research was needed in this area. This paper reports on a number of further short term studies which have followed on from the initial study: change in flow behavior, removal of metals when applied with sediment, distribution of pollutants within the paving structure and particle size distributions with depth. 


\section{Methods}

\subsection{Test Rigs}

The test rigs used in the previous research project (Figure 1) were used again. The two control panels (Rigs A \& B), which only had water applied were loaded with metals and sediment. Rigs C and D had sediment only applied to the surface to test the retention of sediment. All test rigs were situated at the test site near Dundee Airport and were $1 \mathrm{~m} \times 1 \mathrm{~m}$ in plan with a total depth of $0.5 \mathrm{~m}$.

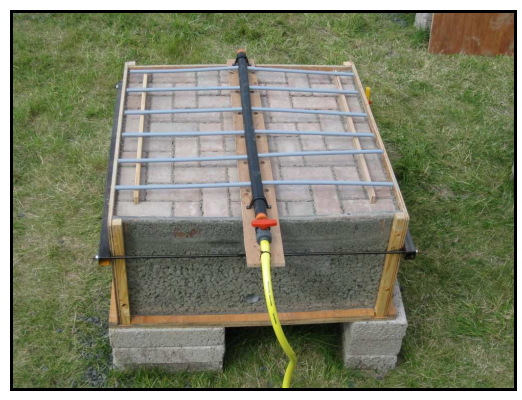

Figure 1. Completed test rig

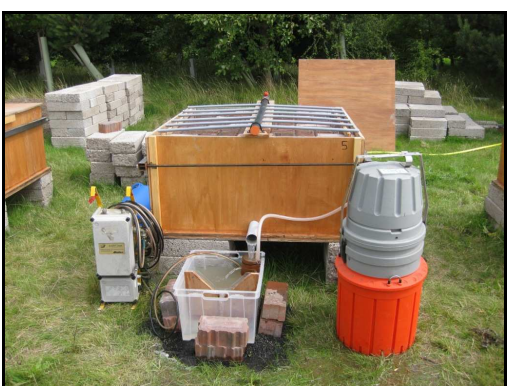

Figure 2. Monitoring set up

The rigs were constructed in plywood with an acrylic 'window'. Rainfall was simulated using the same branch sprinkler system used in the previous project (Mullaney et al, 2011). The UK annual average rainfall is $1200 \mathrm{~mm}$ (Met Office, 2010), therefore 1200 litres was applied to the paving rig by gravity. During the tests all flow from the paving rig was measured using a v-notch weir; the depth over the weir being measured using a pressure transducer to enable a flow rate and volume to be calculated. Samples were collected every two minutes using Epic automatic samplers. Samples were consolidated and three composite samples were used for analysis. The monitoring set up is shown in Figure 2 and the different test regimes in Table 1.

\begin{tabular}{|c|c|c|}
\hline Rig Number & Construction & Test \\
\hline A & No geotextile $(\mathrm{NG})$ & Sediment and pollution profiling \\
\hline B & Geotextile $(\mathrm{G})$ & Sediment and pollution profiling \\
\hline C & No geotextile $(\mathrm{NG})$ & Sediment retention \\
\hline D & Geotextile $(\mathrm{G})$ & Sediment retention \\
\hline
\end{tabular}

Table 1. Test Rig Details

\subsection{Experimental Procedure}

\section{Sediment retention}

The retention of sediment was tested by adding known volumes of sediment before a rainfall event (Figure 3). A total of 20 years of sediment was applied to Rigs C and D, 220g (per $\mathrm{m}^{2}$ ) being chosen to represent the equivalent of one year of sediment, the study by Brown et al (2009) also simulated the application of a total of 20 years runoff and sediment application. The sediment was sprinkled onto the paving surface and watered in using 15 litres of water

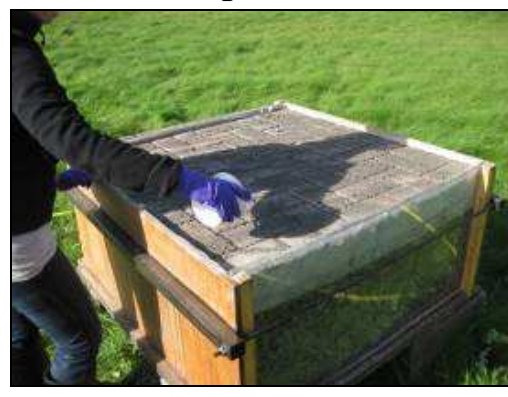

Figure 3. Sediment application

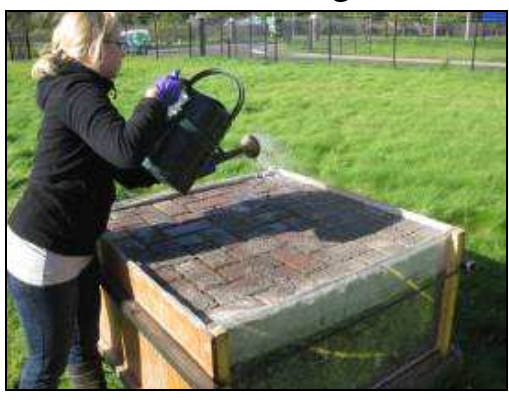

Figure 4. Watering in 
prior to rainfall simulation (Figure 4). Sediment was applied in batches of 3, 3, 4, 5 and 5 years with the equivalent of one year of rainfall applied after each sediment application. Flow volume and time was recorded throughout the application of the simulated rainfall.

\section{Removal of contaminants}

Sediment and metals were applied to Rigs A and B. The earlier sediment retention experiment results were used as guidance for the number of years of sediment which caused a decrease in the infiltration rate. This load was then applied to the test rigs in batches of 3, 3 and 4 years. Water samples were taken during the final rainfall simulation run to establish a background concentration of contaminants and metals.

The same metals applied in the initial study (copper, cadmium, lead, nickel and zinc) were bought in solution at the required concentrations and a 'cocktail' of metals was added to the water tank in soluble form. The water in the tank was then mixed before the solution was spread on the paving area using the sprinkler system. The equivalent of ten years of metals was applied in batches of 1,2 and 7 years. Samples were taken during the last run, after a total of 10 years of metals.

\section{Pollution and sediment profiling}

All samples were taken from the centre of the test rig at the locations shown in Figure 5. Any sediment remaining on the surface of the test rig (1) was collected and then the rig was carefully taken apart. Sediment which had gathered between the blocks was dusted off the blocks and collected (2); samples were also taken from the lower $20 \mathrm{~mm}$ of the upper sub base (3) and from the surface of the geotextile (4). Samples were dried, weighed and analyzed either for pollutant concentration or particle size. The sample locations were similar to those used in the study by Brown et al (2009); samples being taken from the top $25 \mathrm{~mm}$ of joint filler, bottom $55 \mathrm{~mm}$ of joint filler, bedding course, top of the geotextile and three samples from within the base course.

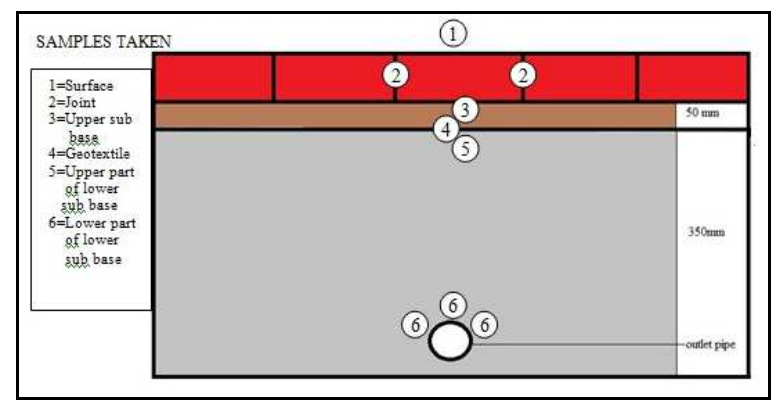

Figure 5. Sample point locations

Sediment profiling was carried out to determine the distribution of different particle sizes within the test rig. The samples were sieved to determine the percentage of the different particle sizes at each sample location. To develop a pollution profile of the test rigs a known amount of dried sediment taken from a sample point indicated in Figure 5 was mixed in 1 litre of distilled water to wash off pollutants. The water samples were allowed to settle out and a sample was taken from the supernatant and sent for analysis.

\section{Results and Discussion}

\section{Change in flow behavior}

In order to understand fully the data from the current work information from the trial runs reported in Mullaney et al (2011) must be considered. 
The sediment applied to the test rigs caused increased pooling and overflowing of water as the total sediment mass applied increased (Figures $6 \& 7$ ). This was a result of lower infiltration rates into the paving structure caused by the sediment blocking the gaps within the surface of the paving. After the equivalent of 10 years of sediment had been applied, both rigs showed significantly more pooling during watering in. Figure 8 is an illustration of the simulated rainfall passing through the paving unit.

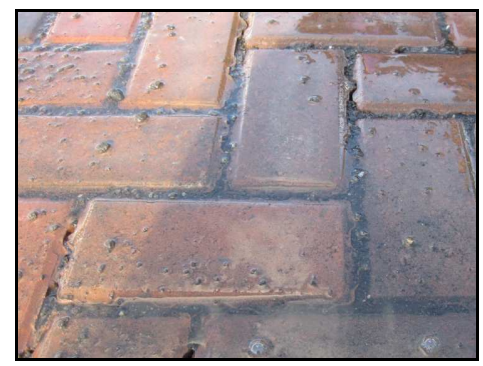

Figure 6. Pooling Rig D after 3yrs

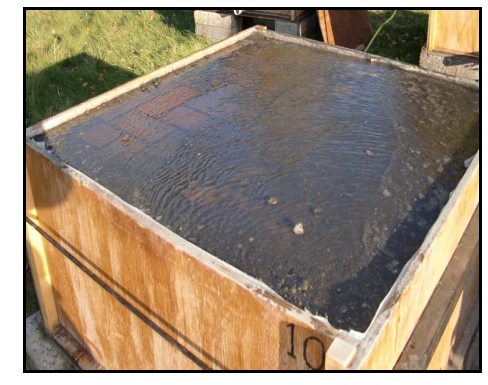

Figure 7. Overflowing after 20yrs

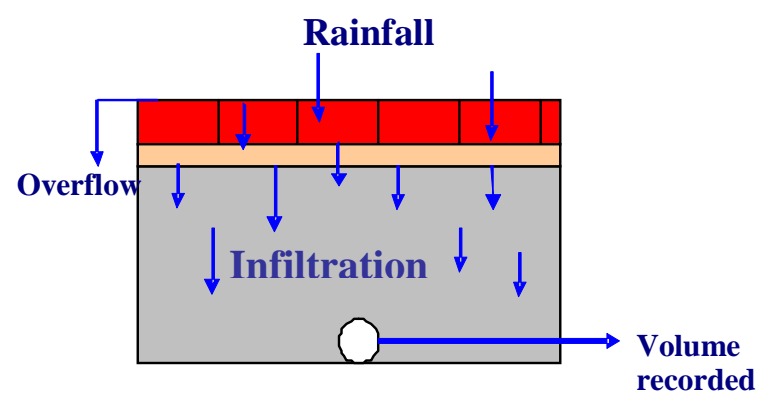

Figure 8. Flow measurement

After 15 and 20 years of sediment application, progressively reduced infiltration rates were noted from both test rigs (Figures $9 \& 10$ ). It is evident from these graphs that rig D (G) had a much lower infiltration rate than rig $\mathrm{C}$ even though the duration of flow was similar. Clearly some of the applied water was lost due to overflowing of the test rig. This may have been exacerbated in the rig with a geotextile by sediment blocking the geotextile causing the reduced infiltration rate. However, since water did not remain on the surface after rainfall, it can be assumed that neither unit blocked entirely.

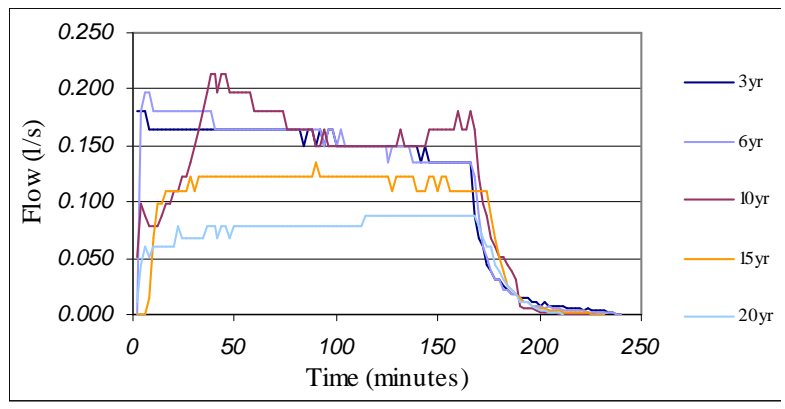

Figure 9. Non-geotextile flow rate (Rig C)

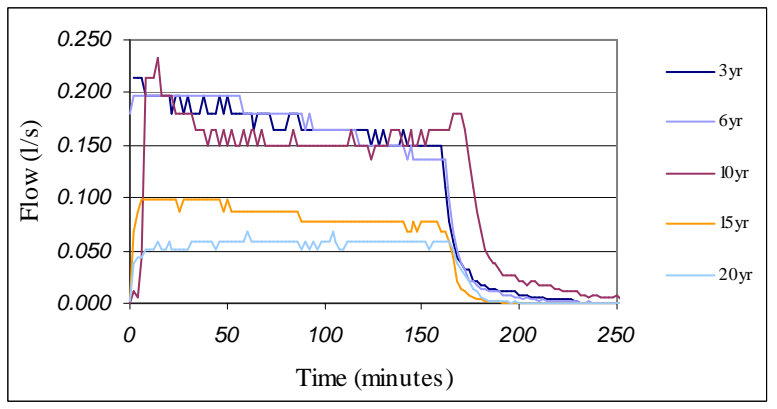

Figure 10. Geotextile flow rate (Rig D)

Consequently from the earlier work it was decided that 10 years of sediment would be used during the pollution and sediment profiling study reported here. 


\section{Removal of contaminants}

In the earlier study by Mullaney et al (2011) there were minimal differences in the percentage of metal removal in the test rigs with a geotextile in comparison with those without. Figure 11 shows that rig $B(\mathrm{G})$ removed slightly greater percentages of metals than rig A; between $1 \%$ and $7 \%$ more, which, although insufficient data were gathered for statistical analysis, is deemed insignificant. When comparing the metal removal results from rigs $\mathrm{A}$ and $\mathrm{B}$ to the removal rates found in the earlier study it is evident that the sediment had an effect on the removal rates. Figure 12 shows that the rigs in the earlier study where metals and metals and oils were applied (rigs 1,2,7 \& 8) removed greater percentages than the rigs in the current study which had metal and sediment applied (rigs A and B). All six test rigs (both studies) removed similar percentages of copper and lead but percentages of cadmium, nickel and zinc were much lower in rigs A and B compared to those in the previous study. The behavior of nickel was different and could not be explained.

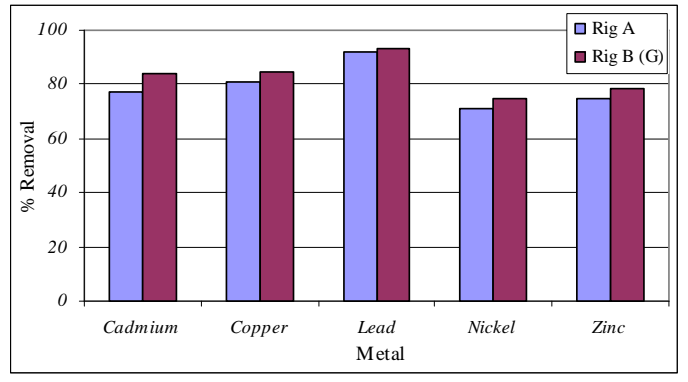

Figure 11. \% metal removal in rigs A \& B

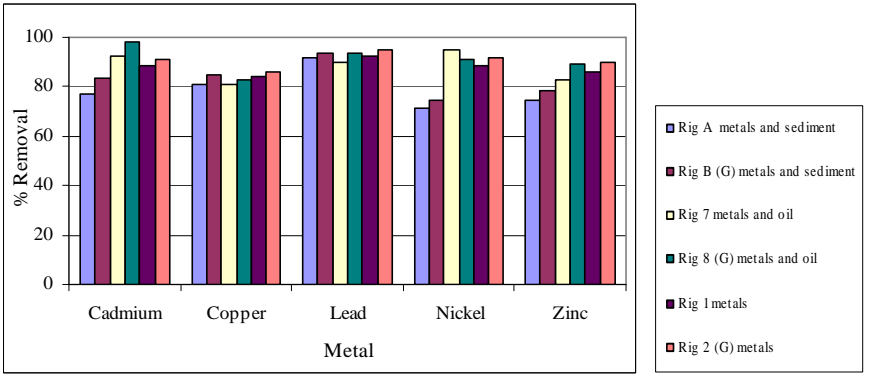

Figure 12. Metal removal rates

\section{Sediment profiling}

Figure 13 shows the particle size distributions from the samples taken during the disassembling of the paving rigs. The cumulative percentage represents the amount of sediment that has passed through that sieve size. It is clear that the results for the two rigs are similar and that a change has taken place between the surface and the geotextile. A higher proportion of coarser material was recorded between the blocks than there was on the surface and this effect was replicated lower down into the bedding material.

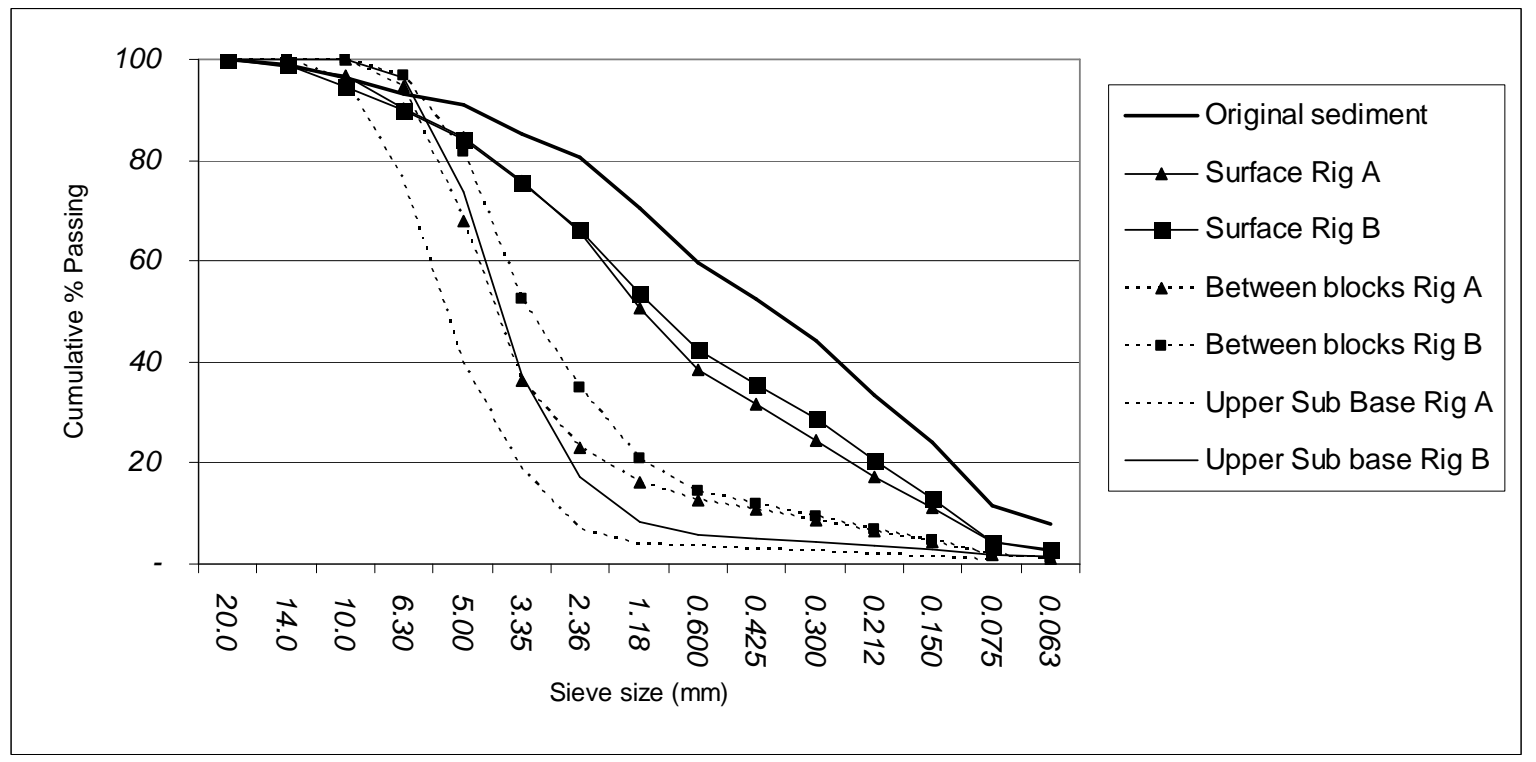

Figure 13. Particle size distributions in permeable paving 
Figure 14 shows the sediment ridges formed between the blocks and also indicates that this has prevented further migration of smaller particles. The sediment had become trapped within the gaps of the paving blocks and has remained on the surface of the bedding layer with little passing through. Unfortunately the experimental technique did not enable a mass balance of sediment applied to be carried out.

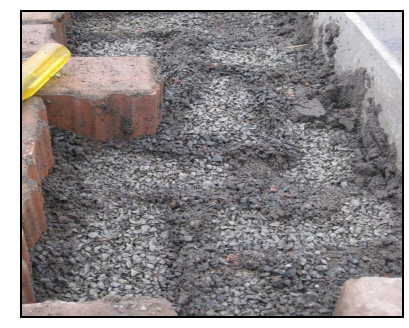

Figure 14. Sediment ridges

\section{Pollution Profiling}

The results from the samples taken at various depths within the paving structure showed that the greatest percentage of metals were concentrated on or above the geotextile in the case of lead, copper and cadmium, shown in Figure 15. However, concentrations of nickel and zinc were highest in the lower sub-base, particularly around the outlet pipe and on the geotextile of rig B (Figure 16). The greatest concentration for all metals was in the surface sediment usually between $40-60 \%$ showing that the majority of metals are trapped within the top layers of the paving structure.

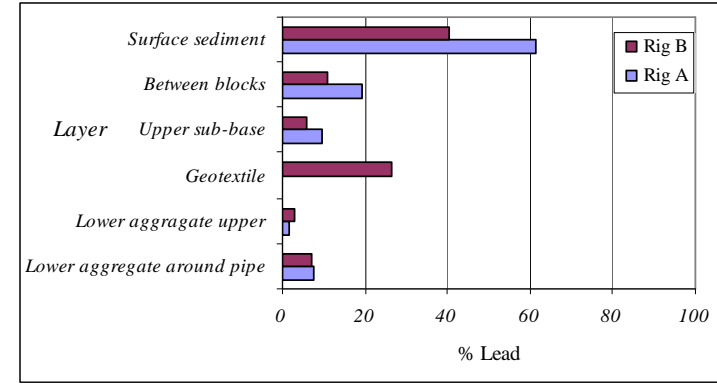

Figure 15. Lead concentration distribution

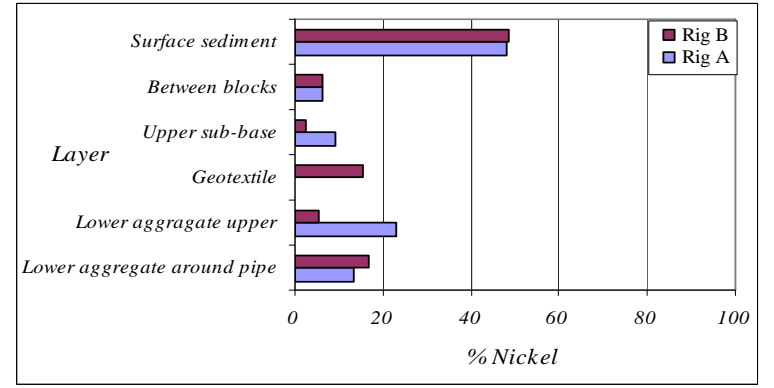

Figure 16. Nickel concentration distribution

\section{Conclusion}

Extremely high loads of street dust were used to simulate blocking of the gaps in the pavement structure and blockages occurred causing overflowing as would be expected. No water overflowed from the rigs during loads up to the equivalent of 10 years of sediment but the effect commenced between 10 and 15 years of sediment application. Flow volumes recorded from the test rigs showed that during years 3, 6 and 10 volumes were similar, however in years 15 and 20 the flow decreased as a result of a decline in infiltration rate which was directly caused by the increased sediment load. The inclusion of a geotextile had no significant effect on water retention but flows from the rig with a geotextile were slightly lower in years 15 and 20 compared to the rig without a geotextile. This may be a result of sediment build up on the geotextile reducing infiltration rates. Neither rig became entirely blocked.

Rigs A and B removed high percentages of metals with between 70 and $90 \%$ being removed. The rig with a geotextile removed between 1 and $7 \%$ more than the rig without a geotextile but this difference is insignificant. When comparing the metal removal results to those compared with an earlier study, it is evident that sediment has had an effect on the metal removal capabilities by removing much greater percentages.

The results from pollution profiling identified that the greatest percentage of metals was concentrated on or above the geotextile in the case of lead, copper and cadmium. However the 
concentration of nickel and zinc were higher in the lower sub base particularly around the outlet pipe compares to other metals (point 6 in Figure 5). The greatest concentration for all metals was in the surface sediment, usually between 40 and $60 \%$. The rig with a geotextile had a lower concentration of metals in the upper sub base than in the rig without, indicating that although both rigs removed similar percentages of metals they were removed within different layers within the paving structure. These data point to the important conclusion that the majority of pollutants (up to 60\% are retained in the upper layer, i.e. they are associated with the blocks. This means that in the vast majority of cases, removal of the blocks and bedding layer will rectify the pollutant removal performance of the system and there is no need to remove the sub-base layer material. Coincidentally, this will also significantly improve the infiltration performance of permeable paving systems which have become partially blocked by sediment.

The equivalent of twenty years of sediment was applied to paving units in batches, each being watered in with one year's equivalent rainfall. The test rigs were carefully taken apart to allow particle size distributions at different depths to be determined. Unfortunately it is difficult to explain the particle size distributions found. It had been expected to find progressively higher proportions of finer material with depth in the paving block structure. However, the reverse was true, with a higher proportion of fines in the sediment applied to the surface and a progressive increase in the proportion of coarse material with depth.

One observation which was expected was that deposited material below the geotextile was much finer than that above, demonstrating the filtration role of the geotextile.

\section{References}

Bean, E.Z, Hunt, W.F, Bidelspach, D.A. and Burak, R.J. (2004) Study on the surface infiltration rates of permeable pavements, 1st Water and Environment Specialty Conference of the Canadian Society for Civil Engineering, Saskatoon, Saskatchewan, Canada, 2-5 June 2004

Brown, C. Chu, A. Van Duin, B. and Valeo, C. (2009) Characteristics of sediment removal in two types of permeable pavement, Water Quality Research Journal of Canada, Vol 44, issue 1, pp.59-70.

Davies, J.W, Pratt, C.J, and Scott, M.A. (2002) Laboratory study of permeable pavement systems to support hydraulic modeling, Proceedings of $9^{\text {th }}$ International Conference on Urban Drainage, Portland Oregon, 5-13 September 2002.

Gilbert, J.K and Clausen, J.C. (2006) Stormwater runoff quality and quantity from asphalt, paver, and crushed stone driveways in Connecticut, Water Research, Vol 40, pp. 826-832.

Met Office. 2010. [online] Available at:

http://www.metoffice.gov.uk/climate/uk/2009/annual/averages.html, [Accessed 03/05/2010]

Mullaney, J, Jefferies, C. and Mackinnon, E. (2011) The performance of block paving with and without a geotextile. Proceedings of the $12^{\text {th }}$ International Conference on Urban Drainage, Porto Alegre, Brazil 2011 September.

Pezzaniti, D, Beecham, S and Kandasamy, J (2009) Influence of clogging on the effective life of permeable pavements Proceedings of the institution of civil engineers-water management, volume 162, issue 3, pp. 211-220. 
Puehmeier, T and Newman, A.P. (2008) Oil retaining and treating geotextile for pavement application, $11^{\text {th }}$ International Conference on Urban Drainage, Edinburgh, Scotland, UK.

Van Duin, B, Brown, Cm Chu, A, Marsalek, J and Valoe, C (2008) "Characterization of long-term solids removal and clogging processes in two types of permeable pavement under cold climate conditions", Proceedings of the $11^{\text {th }}$ International conference on urban drainage, Edinburgh Scotland.

Woods-Ballard, B., Kellagher, R., Martin, P., Jefferies, C., Bray, R. and Shaffer, P. (2007) The SUDS manual. London: CIRIA

Yong, C.F, Deletic, A, Fletcher, T.D and Grace, M.R, (2008) The clogging behaviour and treatment efficiency of a range of porous pavements, Proceeding of the $11^{\text {th }}$ international conference on urban drainage, Edinburgh, Scotland, UK.

\section{About the authors}

Chris Jefferies is a world leader in the design, planning and operation of sustainable urban drainage systems (SUDS), particularly serving highways and has undertaken extensive research in a range of aspects of the ability of SUDS to control contamination from runoff. He is a co-author of the seminal design manual 'The SUDS Design Manual' and has published widely in the field.

Jennifer Mullaney graduated with a degree in Geography and environmental science in 2006 and has worked for the past five years managing a wide range of water and wastewater monitoring and assessment projects. Her recent research has been on the understanding of the behaviour of geotextile fabric in sustainable drainage systems.

Paivi Rikalainen is a student at Vaasa University. 